\title{
Nutrient Export in Run-Off from an In-Field Cattle Overwintering Site in East-Central Saskatchewan
}

\author{
A. Smith ${ }^{1}$, J. Schoenau ${ }^{1}$, H.A. Lardner ${ }^{2,3}$, J. Elliott ${ }^{4}$ \\ ${ }^{1}$ Dept. Soil Science, University of Saskatchewan, Saskatoon, SK, S7N 5A8 \\ ${ }^{2}$ Western Beef Development Centre, Humboldt, SK, S0K 2A0 \\ ${ }^{3}$ Dept. of Animal \& Poultry Science, University of Saskatchewan, Saskatoon, SK, S7N 5A8 \\ ${ }^{4}$ National Hydrology Research Center, Environment Canada, 11 Innovation Blvd., Saskatoon, \\ SK, S7N 3H5
}

Keywords: Run-off, Nitrate, Ammonium, Orthophosphate, Winterfeeding, Saskatchewan

\section{Introduction}

On the Canadian prairies, many cow-calf producers are adopting an in-field overwintering system instead of the feeding cows in more traditional in-yard pen overwintering system. The in-field system can potentially lower cost of production due to reduced yardage and manure hauling costs. The in-field overwintering system was shown in previous research to increase retention and recycling of nutrients contained in feed because nutrients are applied directly to the field instead of being lost in the pen before being transferred to the field (Jungnitsch, 2008). Increased return of nutrients to the soil and potential loading with high stocking rates in the field raises the concern with prospective nutrient transport in runoff. This study examines nutrient export in run-off water from paired watersheds in which cattle were fed in-field over the winter of 2008-2009 versus controls in which no winter feeding took place.

\section{Hypothesis}

The concentrations of phosphorus and nitrogen in snowmelt runoff water from winter feeding sites will be elevated.

\section{Objectives}

To determine the influence of in-field feeding and overwintering of cows on the concentrations of ammonium, nitrate and orthophosphate in snow melt run-off water accumulated in catchment basins.

To assess the effect of winterfeeding versus no winterfeeding on the labile, exchangeable levels of nitrogen and phosphorus in the soil surface $(0-10 \mathrm{~cm})$ layer. 


\section{Materials and Methods}

The study was on a Russian wild ryegrass pasture at the Western Beef Development Center near Lanigan, Saskatchewan that had no cattle or fertilizer applied in the past five years. The terrain in the field is hummocky, creating ephemeral wetlands for the runoff water to collect. The pasture was divided into a control containing four basins and a winterfeeding portion with four basins. Wells and piezometers were installed in all eight basins. Data loggers were installed in two of the winterfeeding basins and two of the control basins to monitor the melt.

Soil samples were collected in the fall 2008. Approximately 100 cattle were wintered on the winterfeeding portion of the pasture for 3 months. They were bale fed using electric fence to control access. After the cows were removed form the pasture a snow survey was completed. On March 31 runoff water collection started and continued daily until the spring melt was complete. Piezometer samples were collected weekly starting in April and continued until the beginning of July. Soil samples were taken again after spring melt in May 2009.

\section{Results}

Concentrations of orthophosphate collected in the snowmelt runoff water from the in-field overwintering sites were significantly elevated compared to water from the control watersheds (Figure 1). Ammonium in runoff water was also significantly elevated compared to the control water. There was no significant difference in nitrate concentrations in water from the overwintering sites versus the control. The lack of effect on nitrate is attributed to dominance of organic $\mathrm{N}$ and ammonium in dung and urine deposited, with cold temperatures limiting conversion of ammonium to nitrate. Piezometer well samples also showed some elevation of ammonium and orthophosphate in the overwintering sites that may have originated from the catchment basins.

There was no significant difference in soluble or exchangeable phosphate in the soil samples taken from winter feeding and control grids set up across the watersheds in May. This likely reflects the rapid uptake of residual manure phosphate by the pasture grass in the spring 


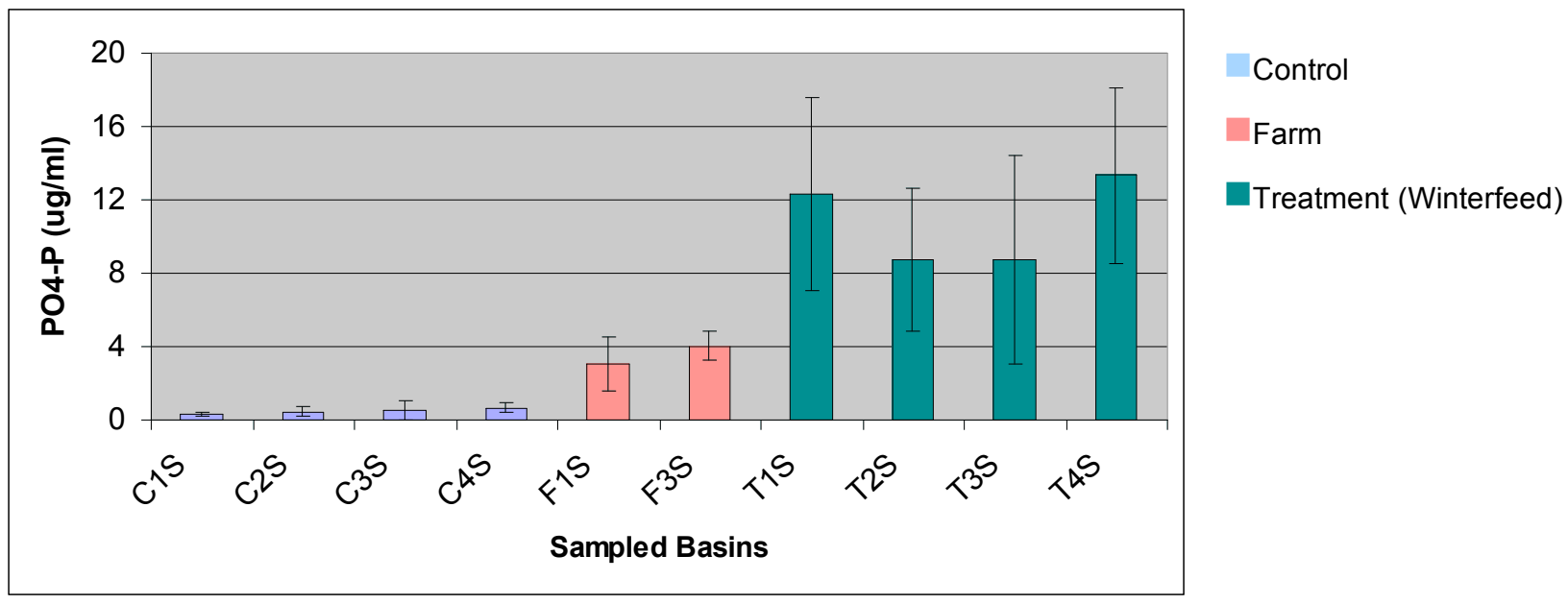

Figure 1. Average orthophosphate (SRP) concentration in water collected from surface runoff starting March 31 until April 19. C indicates control, F farmyard, and T treatment watersheds.

\section{Conclusion}

Elevation of ammonium and orthophosphate concentrations in runoff water from winter feeding sites indicates that these sites should be located in the landscape to avoid run-off water entering into sensitive surface and sub-surface water bodies. Similar nitrate concentrations in runoff water from control and winterfeeding sites may be explained by cool temperatures limiting microbial conversion of ammonium to nitrate. Lower soluble and exchangeable soil phosphate in spring compared to fall may be explained by rapid plant and microbial uptake of $\mathrm{P}$ in spring. Lack of significant effect of winterfeeding on soluble and exchangeable soil phosphate suggests reduced potential for future transport of orthophosphate.

\section{References}

Jungnitsch, P.F.. 2008. The effect of cattle winter feeding systems on soil nutrients, forage growth, animal, performance, and economics. Saskatoon, Canada: M.Sc. Thesis. Head of the Department of Soil Science. 